\title{
Qualitative differences in the maze performance of rats with septal lesions'
}

PAUL ELLEN and GWEN BATE, Georgia State College, Atlanta, Ga. 30303

Septally lesioned, neo-cortical, and sham-operated rats were trained in a Dashiell maze with food reward for 37 days. No differences were found between groups in number of errors. number of errorless paths chosen, or number of different errorless paths chosen, even when the positions of the start and goal boxes were changed. However, qualitative differences were apparent in the kinds of paths chosen; septals took peripheral paths more frequently while controls took central paths more often. The findings suggest that in the absence of extereoceptive cues, septal rats fail to use response-produced, proprioceptive stimuli as discriminaive cues for alternation of turns in the maze.

A number of studies have demonstrated an overresponding tendency in rats following septal damage. This has been manifested as a deficit in passive-avoidance (McCleary, 1961) and position-reversal (Zucker \& McCleary, 1964) tasks, and as increased response rates in operant studies using food reinforcement (Ellen \& Powell, 1962, 1964). In addition, Schwartzbaum, Kellicutt, Spieth, \& Thompson (1964) reported prolonged extinction as a result of septal lesions.

Bilateral hippocampal damage has been reported to have produced perseverative behaviors strikingly similar to that produced by septal damage (Teitelbaum \& Milner, 1963). Kimble (1963) observed that hippocampally damaged rats showed repetitive tracings of the side alleys in Hebb-Williams mazes and that this resulted in significantly more errors for the hippocampal Ss. Kimble \& Kimble (1965) reported further evidence for response perseveration when hippocampal animals were tested on repeated reversals in a Y maze. Niki (1966) found similar results when rats were observed in a Dashiell maze: Hippocampal animals made more errors and were less flexible than normals in choosing different paths and in shifting paths on consecutive days.

To the extent that previous behavioral studies have demonstrated major similarities between animals with septal and hippocampal lesions, and to the extent that a common functional system mediating response inhibition is implicated by these lesions (McCleary, 1966), it would be expected that septally lesioned rats would show less variability in the number of paths chosen in a Dashiell maze, and would be significantly impaired in learning a new path configuration following a change in the position of the start box. The present experiment was conducted to test the above hypothesis.

\section{METHOD}

The Ss were 15 naive, male Long-Evans hooded rats approximately 100 days old and weighing $238.311 \mathrm{~g}$ at the start of the experiment. The apparatus was a checkerboard maze with dimensions described by Dashiell (1930). Modifications of Dashiell's design included higher posts and walls (11 in.) and no top covering; goal and start boxes, 10 in. long, were separated from the maze by guillotine doors. The maze, painted flat hluck, was placed on a table in the center of a room with two fluorescent lights centered overhead.

Preoperatively, Ss were housed three per cage with ad lib food and water. and were handled $2.5 \mathrm{~min}$ each day for six days. Subsequently, the animals were divided into three groups: sham-operated, cortically-lesioned, and septally-lesioned. Since three animals died after anesthetization, data is reported for $12 \mathrm{Ss}$ : five corticals, four septals, and three shams.

Septal and cortical rats sustained electrolytic lesions using a stereotaxic instrument. Nembutal anesthesia $(40 \mathrm{mg} / \mathrm{kg})$ was supplemented by atropine sulfate $(0.16 \mathrm{mg})$ to reduce respiratory distress. The electrode was inserted $1 \mathrm{~mm}$ anterior to Bregma; for septal lesions, the electrode was lowered $5.5 \mathrm{~mm}$ below the surface of the brain, while for the cortical group the depth was $1 \mathrm{~mm}$. Lesions were produced by passing $2 \mathrm{~mA}$ for $15 \mathrm{sec}$ between the anodal electrode in the brain and a probe at the wound margin. Sham-operated rats were placed in the stereotaxic instrument, and the operating procedure followed that for the lesioned animals except that the electrode was not introduced into the brain. Following surgery, all animals
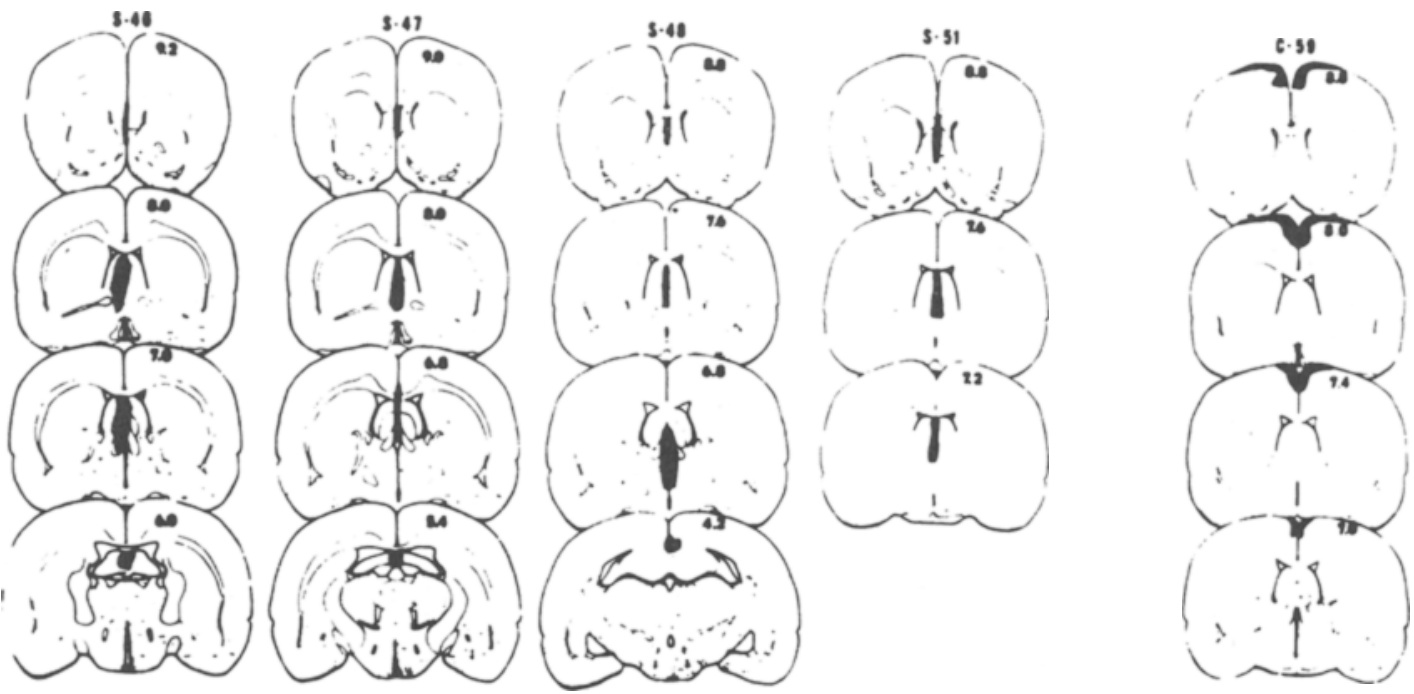

Fig. 1. Reconstruction of lesions for the four septal animals and one representative cortical animal. The lesions are indicated on frontal, diagrammatic sections from the Pellegrino and Cushman Atlas (1967). Each section is identified with the appropriate A.P. stereotaxic coordinates. Anterior brain tissue of S 51 is not shown because of damage during histology. 
Table 1

Average Scores for Various Indices of Maze Performance

\begin{tabular}{|c|c|c|c|c|c|c|c|c|c|c|c|c|}
\hline \multirow{2}{*}{$\frac{\text { Groups }}{\text { Phases** }}$} & \multicolumn{3}{|c|}{ Septal $N=4$} & \multicolumn{3}{|c|}{ Cortical $N=5$} & \multicolumn{3}{|c|}{ Sham N = 3} & \multicolumn{3}{|c|}{ F Values* } \\
\hline & 1 & 2 & 3 & 1 & 2 & 3 & 1 & 2 & 3 & 1 & 2 & 3 \\
\hline $\begin{array}{l}\text { Errors } \\
\text { Errorless }\end{array}$ & 24 & 13 & 5 & 23 & 9 & 3 & 15 & 17 & 8 & .73 & .66 & 3.81 \\
\hline $\begin{array}{l}\text { Paths } \\
\text { Different }\end{array}$ & 8 & 5 & 7 & 9 & 6 & 8 & 10 & 6 & 6 & .27 & .31 & 1.18 \\
\hline $\begin{array}{l}\text { Paths } \\
\text { Inside }\end{array}$ & 4 & - & 2 & 5 & - & 3 & 7 & - & 3 & 3.68 & - & .82 \\
\hline $\begin{array}{l}\text { Paths } \\
\text { Outside }\end{array}$ & 2 & - & 1 & 6 & - & 3 & 8 & -- & 2 & & & \\
\hline Paths & 6 & - & 6 & 3 & - & 5 & 2 & - & 4 & & & \\
\hline
\end{tabular}

- For $F$ values listed, $d f=2 / 9, p>$.05.

* Phase 1, 17 days; Phase 2, 10 days; Phase 3, 10 days.

received $0.2 \mathrm{cc}$ Duracillin and were housed in separate cages with ad lib food and water.

On the fourth postoperative day, Ss were placed on a 23-h fooddeprivation schedule, and began 12 days of training to run in a straight alley with $30 \mathrm{~g}$ wet mash mixed with canned figh and tomato soup as reward. Subsequently, each $S$ received one trial per day for 37 days in the Dashiell maze with reinforcement as described above. Ss were placed in the start box and removed from the goal box by the E. Guillotine doors were operated manually. At the end of each trial, $S$ was returned to the home cage and allowed to finish eating.

For the first 17 trials, Phase 1, the start and goal boxes were placed on diagonally opposite corners. In Phase 2, Days 18-27, the start box was shifted one corner to the right. On Days 28-37, Phase 3 , the goal box was repositioned one comer to the right, restoring a diagonal path configuration.

At the end of behavioral testing, Ss were sacrificed with a lethal dose of Nembutal and perfused intracardially with isotonic saline followed by $10 \%$ formalin. Frozen-tissue technique was used to section the brains $(50 \mu$ thickness). Every fifth section was mounted and stained with cresylechtviolet for histological analysis. Typical lesions are shown in Fig. 1.

\section{RESULTS AND DISCUSSION}

Table 1 shows the group means for each of the various indices of maze performance. Two measures of acquisition were used: errors and errorless paths. An error was counted whenever the animal entered a blind alley or turned away from the goal. An errorless path was one in which no errors occurred. Thus, whether a path contained a single error or multiple errors, it did not meet the criterion for an errorless path. The measure of variability was simply the number of different errorless paths taken during Phases 1 and 3 when the animal could choose one of 20 different routes of equal distance to the goal on each trial. Analysis of data obtained from the path tracings of each trial revealed no significant differences between groups in any of the phases on measures reflecting acquisition and/or response variability (see Table 1).

The failure to show a perseverative tendency following septal lesions contrasts with previous studies cited above which reported response perseveration following septal damage. However, it should be noted that in a Dashiell maze the animal is not penalized for responding. McCleary (1966) has pointed out that only in tasks when a normal animal is penalized for continuing to respond does the septal overresponding become apparent. This may account for the differences in findings between this and other studies.

Although septal animals did not differ from controls or cortically-lesioned animals in either measure of acquisition or in response variability, they did behave differently in terms of the kinds of routes chosen. Comparison of peripheral, L-shaped routes and central, zigzag routes in the initial phase of training showed that septal rats ran peripheral paths significantly more frequently than cortical $(F=5.86, \mathrm{df}=1 / 7$, $p<.05)$ or normal animals $(F=6.23, \mathrm{df}=1 / 5, \mathrm{p}<.05)$. The preference for a zigzag path by control Ss is consistent with findings of Dashiell \& Bayroff (1931) which demonstrated a tendency for normal rats to altemate right and left turns in locomotion through a maze.

The differences in the kind of route chosen by septal animals suggests a difference in the nature of the stimuli controlling the maze performance of these animals. In order to run inside, zigzag paths, the animal must alternate turns, a behavior requiring the discrimination of response-produced stimuli since no differential exteroceptive cues are available in the maze. The findings in this study are consistent with those of other studies in which septal animals were impaired in making spatial reversals in a task in which only responseproduced feedback was available (Zucker, 1965; Zucker \& McCleary, 1964). Apparently, septal animals are impaired in the utilization of response-produced cues.

\section{REFERENCES}

DASHIELL, J. F. Direction orientation in maze running by the white rat. Comparative Psychology Monograph, 1930, 7, 1-72.

DASHIELL, J. F., \& BAYROFF, A. G. A forward-going tendency in maze running. Joumal of Comparative Psychology, $1931,12,77-94$.

ELLEN, P., \& POWELL, E. W. Effects of septal lesions on behavior generated by positive reinforcement. Experimental Neurology, 1962 , $6,1 \cdot 11$.

ELLEN, P., WILSON, A. S., \& POWELl, E. W. Septal inhibition and timing behavior in the rat. Experimental Neurology, 1964, 10, $120-132$.

KIMBLE, D. P. The effects of bilateral hippocampal lesions in rats. Journal of Comparative \& Physiological Psychology, 1963, 56, 273-283.

KIMBLE, D. P., \& KIMBLE, R. J. Hippocampectomy and response perseveration in the rat. Joumal of Comparative \& Physiological Psychology, 1965, 60, 474-476.

McCLEARY, R. A. Response specificity in the behavioral effects of limbic system lesions in the cat. Journal of Comparative \& Physiological Psychology, 1961, 54, 605-613.

McCLEARY, R. A. Response functions of the limbic system. In $F$. Stellar and J. M. Sprague (Eds.), Progress in physiological psychology. New York: Academic Press, 1966.

NIKI, H. Response perseveration following the hippocampal ablation in the rat. Japanese Psychological Research, 1966, 8, 1-9.

PELLEGRINO, L. J., \& CUSHMAN, A. J, A sterentaxic atlas of the rat brain. New York: Meredith Publishing Co., 1967.

SCHWARTZBAUM, J. S., KELLICUTT, M. H., SPIETH, T. M., \& THOMPSON, J. B. Effect of septal lesions in rats on response inhibition associated with food-reinforced behavior. Journal of Comparative \& Physiological Psychology, 1964, 58, 217-224.

TEITFLBAUM, H., \& MILNER, P. Activity changes following partial hippocampal lesions in rats. Journal of Comparative \& Physiological Psychology, 1963, 56, 284-289.

ZUCKER, I. Effect of lesions of the septal-limbic area on the behavior of cats. Journal of Comparative \& Physiological Psychology, 1965, 60, 344-352.

ZUCKER, I., \& MCCLEARY, R. A. Perseveration in septal cats. Psychonomic Science, 1964, 1, 387-388.

$$
\text { NOTE }
$$

1. This research was supported in part by NSF Grant GB-7184. 